PROCEEDINGS OF THE WORLD CONFERENCE ON OZONE THERAPY IN MEDICINE, DENTISTRY AND VETERINARY. ANCONA (ITALY). SEPTEMBER 22nd - 23rd - 24th, 2017

\title{
The use of ozone in the interventional pain management [abstract]
}

\section{Nurettin Luleci}

Turkey

\section{ABSTRACT}

\section{ว OPEN ACCESS}

\section{Citation}

Luleci N. The use of ozone in the interventional pain management [abstract]. Proceedings of The World Conference on Ozone Therapy in Medicine, Dentistry and Veterinary. Ancona (Italy). September 22nd - 23rd - 24th , 2017. J Ozone Ther. 2019;3(4):33. doi: 10.7203/ jo3t.3.4.2019.15517

\section{Academic Editor}

Jose Baeza-Noci,

School of Medicine, Valencia University, SPAIN

\section{Editor}

World Federation of Ozone Therapy, Bolgna, ITALY

\section{Received}

June 17, 2019

\section{Accepted}

December 08, 2019

\section{Published}

December 30, 2019

\section{Intellectual Property}

Nurettin Luleci.

This is an open access article distributed under the terms of the Creative Commons Attribution License (CC BY 4.0), which permits unrestricted use, distribution, and reproduction in any medium, provided the original author and source are credited.

\section{Author Information}

nluleci@gmail.com
Purpose. Ozone can be successfully used in pain therapy. As being a pain management specialist, I have been using ozone in many cases for a long time. Some of those therapies are minimal invasive therapy that can be applied simply at office where some other need special sterile atmosphere.

Results. We achieved different results in different therapy methods. In sympathetic originated pain, discogenic pain, spinal pain like radicular pain, we apply some different combined therapy techniques as only ozone or ozone combined with different techniques.

Discussion. There are many other therapy methods in pain management. Ozone therapy is one of those methods. Success rate varies comparing to other methods. But ozone is cheap, simple and has only few side effects.

Conclusion. Ozone therapy can be is a very successful therapy tool in pain management. 